\title{
Shifting baseline syndrome among coral reef scientists
}

Milton Muldrow Jr. ${ }^{1 凶}$, Edward C. M. Parsons $^{2} \&$ Robert Jonas ${ }^{2}$

The 'shifting baseline syndrome' has received much attention and acceptance within the conservation science community. In this study, the 'shifting baseline syndrome' based on which each generation of fisheries scientists accepts the stock size and species composition extant in the beginning of their careers as the normal baseline, as proposed by Pauly in 1995, was tested. It was hypothesized that Florida Keys reef scientists use the reef conditions at the beginning of their careers as the baseline for the evaluation of change. A cohort of these scientists was used as a study group to test this hypothesis and explore expert opinions on reef baselines. Snowball sampling led to a total of 54 interviews of Florida Keys Reefexperienced scientists. Among all contacts, $48 \%$ responded and were interviewed for a total of $37.6 \mathrm{~h}$. Correlation statistics were used to analyse the respondent's age and experience and their correlations with the reported baselines. Ninety-six percent of the interviewees were professional scientists. Baselines for the Florida Keys bank reef ecosystem were established based on the respondents' testimonies. Independent of the age, experience, or affiliation, the respondents agreed that the baselines for the Florida Keys bank reef are a coral cover of $33 \%$ and 44 years before present (1972). Seventy percent of the respondents who were under the age of 40 stated that they never witnessed an Acropora sp.-dominated reef, whereas $96 \%$ of the experts over the age of 60 stated the opposite. This demonstrates the dramatic change in the interaction with the coral reef from one generation of experts to the next; however, the consensus regarding the baselines is high. Our results indicate the general consensus regarding reef baselines among scientists, which may inform the management practices of a wide range of stakeholders. This study provides evidence that Florida Keys reef scientists are not subject to the shifting baseline syndrome, highlighting that education and experience may counter potential baseline shifting. These results can be used as references for the establishment of unified restoration goals in coral restoration programs. Appropriate coral baselines have been debated for decades, with little understanding of the community consensus.

\footnotetext{
${ }^{1}$ Wilmington University, New Castle, DE 19720, USA. ${ }^{2}$ George Mason University, Fairfax City, VA 22030, USA. ${ }^{凶}$ email: Milton.x.muldrow@wilmu.edu
} 


\section{Introduction}

Shifting baseline syndrome. Coral reefs have received much public attention in recent years. Reef communities and the causes of their decline have been more commonly discussed in national news media in comparison to other ecosystems. Therefore, the term 'shifting baseline syndrome' (SBS), which has commonly been used in reef literature as a conservation concern, has been popularised in media (Olsen, 2002; Mooallem, 2017), although rigorous examinations of this idea are scarce (Kahn and Friedman, 1995; Campbell et al., 2009; Papworth et al., 2009; Fernández-Llamazares et al., 2015; Eddy et al., 2018).

In 1995, Pauly (1995) published a highly influential paper (2146 citations as of April 2020), establishing the concept of SBS. Other highly influential papers (Sheppard, 1995; Dayton et al., 1998; Jackson et al., 2001; Saenz-Arroyo et al., 2005; Humphries and Winemiller, 2009; Pinnegar and Engelhard, 2008; Knowlton and Jackson 2008; Baisre, 2013), such as Jackson et al.'s 2001 manuscript (4824 citations as of September 2016) have been published since then, citing the SBS as a great concern for the conservation of species. Pauly (1995) referred to scientists in his original manuscript on SBS as follows: '...each generation of fisheries scientists accepts as a baseline the stock size and species composition that occurred at the beginning of their careers and uses this to evaluate changes'.

Kahn and Friedman were the first to suggest a 'general amnesia' regarding the changes of generational norms with respect to environmental degradation. Papworth et al. (2009) described two SBS types. The first type involves knowledge extinction due to the loss of information between young and old populations, which is the focus of this paper, and the second type refers to personal amnesia based on which individuals forget their experiences.

Campbell et al. (2009) argued that the SBS violates ecological assumptions, for example, (1) that natural baselines exist; (2) that baselines can be accurately described; and (3) that ecological baselines can be restored. Given the research communities' interest in exploring coral baselines, we argue in this study that the baseline represents a metric the scientific community seeks to explore. Soga and Gaston (2018) describe the SBS as a fundamental cause of environmental degradation and outline potential causes and environmental consequences. Eddy et al. (2018) attempted to estimate the worldwide global coral baseline using surveys administered on twitter and a National Oceanic and Atmospheric Administration (NOAA) listserv and found neither a difference between expert baselines and that of other non-expert 'ocean users' nor differences among baselines referring to different times. However, they attempted to estimate a global coral cover baseline, which is not a true baseline because a reef environment in a single geographic area (e.g. Florida or Jamaica) may exhibit various zones and species composition patterns (Goreau, 1959). By not defining a particular site, habitat, depth, or zone, one cannot reasonably assess the SBS of a single reef site, let alone that of the Earth. For example, even under pristine conditions, one would have vastly different expectations regarding a reef located in a bay, reef flat, or bank reef.

Testing the shifting baseline syndrome: three major aims of this study. In this study, three major aspects of the SBS pertaining to Florida Keys Reef experts were evaluated. The first aspect was to evaluate the reef expert opinions on the number of years before present (YBP) and coral cover percentage of the reef baseline. This aspect was also evaluated in the context of the respondent's age, years of experience, and number of dives, that is, variables one would expect to influence the respondent's baseline if the SBS affects the population. The aim was to determine the level of consensus among reef experts regarding the baseline. The results may inform the community of the consensus regarding the 'baseline' and potentially help to establish a unified goal for coral restoration programs. The YBP and coral cover baselines were also compared regarding the respondent's employment category (government vs. nongovernmental employee) to further account for potential variables that may be responsible for differences in the respondents' baselines. This comparison was also used to assess potential differences regarding baseline perceptions among reef experts representing universities, private companies, the public, and non-profit organizations. It is important to highlight the synergy or lack thereof among these different groups of experts because each depends on the other for the management, study, promotion (through outreach), and restoration of the reef environment. With so many organizations involved in reef science, conservation, and policy, the potentials for competing interests, ideas, and goals among these groups are high.

The second aim of this study was to assess the variables that inform the YBP and cover percentage baselines. Understanding how experts evaluate an ecosystem may provide insights into the SBS. It was also important to determine the sources of information they used to derive their baselines. One might assume that experts and scientists would utilize established literature instead of personal experience to determine baselines. However, Pauly (1995) describes the SBS of fisheries scientists, a population similar to reef experts. Generally, scientists utilize a host of information types, such as personal experience, to make decisions. In previous studies, scientists cited a lack of supporting evidence based on which they could draw long-term conclusions about their ecosystem of interest (Cook et al., 2010, 2013; Cvitanovic et al., 2015), leading to a greater reliance on personal experiences. If reef scientists are relying on personal experiences and SBS has an effect, this would presumably be measurable. The question is if the SBS has impaired the professional reef community. Because these individuals are trusted to manage and study this system, it is important to answer this question.

Given the extent of reef damage over the last decades and the fragmented and remote nature of intact reefs within the Florida Keys (McClenachan et al., 2017), the third aim of this study was to evaluate whether reef experts had experienced an Acroporadominated reef, the ecosystem in question. This was also a measure of the potential SBS because the respondent's interaction with a structurally functional reef is partially a function of the age of the respondent. If the SBS has affected the study population, different baselines, partially based on different age-related experiences, are expected. Reef systems in which branching corals are responsible for much of the topographic complexity of certain regions of the Florida Keys Reef were prevalent in the early careers of older respondents. Therefore, they experienced a different ecosystem than younger respondents because many of the corals have perished. The third aim of this study was to evaluate if there is enough evidence to suggest that a difference in the experience associated with different coral baselines.

Florida Keys national marine sanctuary. Caribbean coral reef ecosystems, including the Florida Keys, are significantly and rapidly declining (McClenachan et al., 2017). In recognition of the need to preserve coral environments in Florida, the Florida Keys National Marine Sanctuary (FKNMS) was designated by the Congress in November 1990. It consists of $2896 \mathrm{nmi}^{2}$ and includes 24 highly protected 'no-take' zones, which have been in place since 1997. The FKNMS contains hardbottom, mangrove, patch reef, and seagrass meadow habitats, which are interconnected and support more than 6000 plant, fish, and 


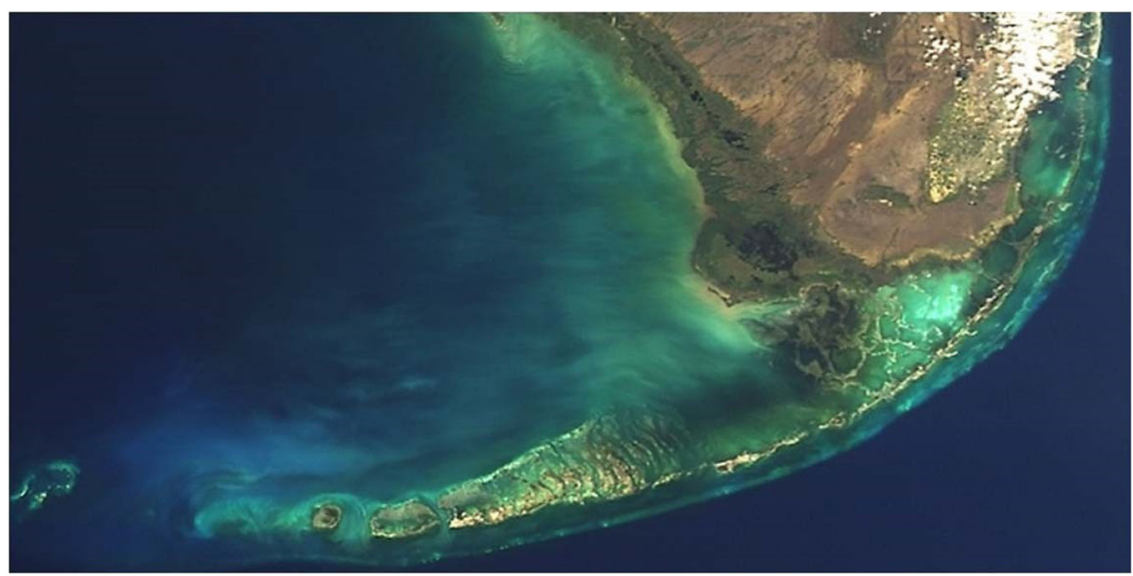

Fig. 1 Satellite image of the Florida Keys island chain. The cover percentage of the bank reef located off the coast of the island chain has steadily declined in recent decades. Climate change, coral disease, and a decline in the overall water quality are factors that affected the decline. Image Credit: USF/WHOI/ MBARI/NASA.

invertebrate species (Office of National Marine Sanctuaries, 2011). Although $\sim 30$ years old, scientists are still trying to establish standards and baselines for comparison to accurately characterise the health of the FKNMS. A noteworthy method is the comparison of current species populations with past ones, although scientists are quickly confronted with the dearth of historical data.

A confluence of factors has contributed to the degradation of coral reef communities within the FKNMS over the last four decades. These include the declining water quality due to sewage pollution (Lapointe et al., 2004), hurricane activity (Lirman and Fong, 1997), mass mortality of Diadema antillarum (Lessios et al., 1984), increased sea temperatures (Hoegh-Guldberg, 1999), and nutrient enrichment in the Florida Bay (Lapointe et al., 2004). The Florida Keys reef tract exhibits a zonation pattern that is common in the Caribbean (Goreau, 1959) in which A. palmata, Montastraea (now Orbicella) annularis, Orbicella annularis, and A. cervicornis are the primary species (Precht and Miller, 2007). Managing the sheer number of threats to the FKNMS is a significant challenge for scientists and further complicates the establishment of baselines given the fundamental changes of the reef environment. These water quality, temperature, and reef structure changes are factors that are not likely to return back to historical norms in a timeframe meaningful to a human life. However, many ecosystems around the globe face such complex issues, although the Florida Keys are a uniquely positioned for study due to their recent management history and the current efforts of scientists and science agencies to establish baselines to inform the management.

History of research conducted on the Florida Keys reef tract. Although patchy and inconsistent, there is a history of scientific analysis of reefs in the Caribbean and Florida Keys. Goreau (1959) was influential in identifying zonation patterns of scleractinian populations in a Jamaican coral reef. Goreau's (1959) description of corals of Jamaica represents the basis for the current knowledge about Caribbean reefs. Many of his observations about corals in Jamaica in the 1950s are in stark contrast to the present. For example, Goreau (1959) noted that living corals covered more than $90 \%$ of the available surface within what he described as the buttress zone of Jamaican coral reefs.

Early studies of reef coral populations in the Florida Keys include that of Dustan (1977) who conducted surveys of the corals in the Carysfort Reef in John Pennekamp State Park, Key Largo, Florida. The Carysfort Reef is a fringing and barrier reef on the edge of the reef line approximately eight miles offshore. $\mathrm{He}$ reported a cover percentage reaching $60 \%$ at a depth of $13 \mathrm{~m}$ but noted a decline in the coral populations during a 14-month interval. For example, Mycetophyllia ferox experienced a mortality of 20 to $30 \%$ within this period.

A subsequent survey was conducted between 1974 and 1982 in the Carysfort Reef using 21 permanently marked line transects, indicating a significant change in the coral reef community during that period (Dustan and Halas, 1987). The authors claimed that the abundance of corals living at depths between 10 and $21 \mathrm{~m}$ decreased by a total of 72 colonies.

Porter and Meier (1992) conducted surveys at six coral reef locations between Miami and Key West from 1984 to 1991 including two photo stations at each location, that is, Looe Key National Marine Sanctuary, Key Largo National Marine Sanctuary (Carysfort Reef), and Biscayne National Park. The maximum percentage cover in the monitored areas was $33 \%$. The loss of live coral cover was reported in five of the six areas, with net losses ranging between $7.3 \%$ and $43.9 \%$.

Based on the Coral Reef Evaluation and Monitoring Project (CREMP), which is a long-term reef-monitoring project, the cover percentage of various reef habitats has been examined since 1996 (Fig. 1). The stony coral cover in all regional habitat areas surveyed by CREMP has significantly decreased since 1996, except for the Middle Keys Patch Reef (Ruzicka et al., 2010). Based on CREMP, the stony coral cover percentage in the Lower Keys backcountry patch reefs dropped from $10.0 \%$ to $2.7 \%$ between 2001 and 2002. Based on CREMP, the coral cover within the deep fore reefs decreased from $6.7 \%$ to $3.7 \%$ between 1996 and 1999 and the stony coral cover in the Lower Keys Patch Reefs decreased from $27.5 \%$ to $19.7 \%$ during the same period. The patch reef coral cover in the Upper Keys dropped from $16.3 \%$ to $11.9 \%$ between 1996 and 1999 . The stony coral cover was 16.0 , $3.9,2.4$, and $2.0 \%$ in the patch, shallow, deep fore-, and backcountry patch reefs, respectively. Seventy percent of the 34 surveyed sites showed a decreasing trend in the coral cover since 1996. Between 1996 and 2014, the macroalgae cover percentage increased from an average of $\sim 8 \%$ to $15 \%$. The octocoral cover percentage also increased, from 13\% in 1996 to $\sim 15 \%$ in 2014 (Florida Fish and Wildlife Conservation Commission, 2016).

An additional study of the coral cover percentage in the Florida Keys was conducted after Hurricane Andrew in 1992 (Lirman and Fong, 1997). Surveys were carried out in the Elkhorn Reef in the northernmost region of the Florida Keys reef tract in Biscayne 
National Park. Surveys were conducted using belt transects through the rubble zone, reef flat, and fore reef.

An average percent coral cover of $42 \%$ was determined, but extensive damage to $A$. palmata due to the hurricane was observed. Both shallow and deep areas of the Carysfort Reef were surveyed within the CREMP program (Ruzicka et al., 2010). At the Carysfort Deep $(\sim 10-20 \mathrm{~m}$ depth), the stony coral cover percentage decreased from $14.3 \%$ to $4.1 \%$ between 1996 and 2008 . The coral cover at the Carysfort Shallow ( 3-6 m depth) declined from 10.9 to $2.9 \%$ between 1996 and 2008 . Based on the survey of the Carysfort Reef by Dustan (1977), the maximum coral coverage was $60 \%$ at a depth of $13 \mathrm{~m}$ ('deep' area). Based on meta-analysis, Gardner et al. (2003) concluded that the average stony corals reef cover across the entire Caribbean basin decreased from $50 \%$ to $10 \%$ between 1977 and 2001, representing an $80 \%$ decline.

In 2005 an extensive bleaching event caused by persistent, elevated sea surface temperatures occurred throughout the Caribbean (Donahue et al., 2008). The bleaching in the Florida Keys was not as severe as in other regions of the Caribbean, although the increased temperatures spurred a lack of resistance to pathogens, causing significant mortality (Eakin et al., 2010).

\section{Materials and methods}

The Florida Keys reef ecosystem and reef experts were used as a model system to explore the SBS as a general hypothesis. Florida was chosen as a model-based system to test the SBS because of its well-established industrial complex of federal and state government agencies, as well as university and non-profit organizations working on issues specific to the health of the Florida Keys reef. The concept of the SBS has previously been applied to the Florida Keys in a number of notable publications (Jackson et al., 2001; McClenachan, 2009; McClenachan et al., 2017). Because of the diversity of coral zonation patterns throughout the Caribbean (Goreau, 1959), establishing a specific region of the reef is vital to generating reliable data. Therefore, the respondents were requested to base their responses on the Florida Keys reef tract and the bank reef and buttress zone at a depth of $10 \mathrm{~m}$.

Experimental design. The aims of this study were to examine (1) the SBS in terms of respondent-reported YBP and baseline coral cover based on their age, years of experience, and number of dives taken, (2) what informed the respondents' baselines, and (3) if the respondents witnessed an Acropora-dominated reef in the Florida Keys using a series of open-ended questions (Appendix I). The responses were compared with the respondents' ages and experiences. The surveyed population (Florida Keys reef experts) was initially identified using an email listserv commonly used by reef experts. Telephone interviews were used for data collection. The data were manually recorded and then entered in a spreadsheet. The surveys were used to assess various topics as part of a broader doctoral dissertation; therefore, the results presented here do not address all questions of the survey listed in Appendix 1.

Regarding the YBP baselines, several respondents provided a specific number of years past, while other respondents provided a range of years; for example, several respondents would say 'the 1970s'. The respondents were asked to determine average baselines. Therefore, the midrange of their responses was calculated (i.e. 1975), which was used as the YBP baseline for this type of response.

Identifying the population for sampling. Snowball sampling, a survey method in which participants suggest further names of study subjects (Bernard, 2002), was used to develop the contact list. It is valuable when subjects are difficult to identify. The benefit of this method is that the sample contact list will ultimately become 'saturated' (no new names will be mentioned by respondents). Reef experts may be found in federal, state, local, non-profit, and private organizations. As such, it was difficult to create a sample without implicit bias regarding the institution type, familiar networks, and subject geography and demographics. Therefore, snowball sampling was ideal for this particular study. A test survey was performed with one 'expert' subject. The survey was not significantly changed after the test and the test subject's testimony was incorporated in this study. The test subject was a reef expert chosen by the author who was not named again by other interviewees.

Potential interviewees were initially contacted via a recruitment email and each expert who responded was asked to suggest other experts on the Florida Keys reef tract. A diverse cohort of experts with different ages and employment types was developed. The recruitment was concluded once there was a significant overlap in the referrals. Experts were interviewed in one-on-one sessions by telephone. The interviews took place between January and May 2016.

Data analysis. The reef experts' definition of the baseline reef, measured in number of years past (time), and the coral cover (Aim 1) were correlated with the respondent's age and experience (years and number of research dives in the Florida Keys). Pearson's correlation coefficient was calculated to measure these relationships. One respondent reported a YBP baseline outlier (6000 years). This response was excluded from the Pearson's correlation statistics to avoid conflict with the basic assumptions of the test. Aims 2 and 3, that is, the evaluations of what informed the respondent's baselines and if the respondents had experienced an Acropora-dominated reef, were evaluated using descriptive statistics including the means and percentages of response types.

All respondents. Eight individuals ('The Seed') responded to an email request on the Coral listserv (http://coral.aoml.noaa.gov/ mailman/listinfo/coral-list). Among the suggested names of interviewees, 94 other individuals were contacted and 45 responded (response rate $=47.9 \%$ ). The last three surveys did not result in new names, indicating the saturation of the sample, as is the standard. The test survey and seed subjects were included in the dataset, leading to a total of 54 survey respondents. The total testimony time is $37.6 \mathrm{~h}$.

The average age of respondents was 56. Twenty-seven individuals worked (or had previously worked) for government agencies, seven worked for NGOs, seven worked for private companies, and 18 worked for universities. For retired respondents, the organization they retired from or for which they had most recently worked was used to represent their employment type. The respondents were also asked about their Florida Keys diving experience. The average number of dives of the respondents is $\sim 2453$. One respondent did not answer this question because they did not know their approximate number of dives. This individual had many years of dive experience; therefore, the total estimated number of dives is likely a low estimate. The 1513 years of cumulative dive experience translate into first-hand eyewitness experience of the coral reef condition and change.

All subjects' names, responses, and personal information were kept completely confidential and the results were reported in aggregate form in accordance with George Mason University's human subjects' policy. 
Table 1 Mean (standard deviation) Years Before Present baselines among various respondent types.

How many years past (if any) would you use as the ecological baseline for the cover percentage for stony corals in the Florida Keys as a guide for setting restoration targets (on average throughout the keys, bank reef, and buttress zone at a depth of $10 \mathrm{~m}$ )?

With outlier

Without outlier $159(826) 52$

Respondents younger than 60 years-without outlier $44(18)$

$44(20)$

$44(17)$

$45(26)$

Government experts-without outlier

$44(9)$

$44(23)$

Respondents with less than 20 years of

$44(15)$

$41(10)$

Respondents with more than 20 years of experience

Experts with less than 1500 dives in the Florida

Keys-with outlier

Experts with more than 1500 dives in the Florida Keys 48 (25) 22

Note: The data contain one outlier. One respondent reported 6000 Years before present (YBP). The closest response to 6000 was 126 YPB. Therefore, the data are represented with and without this outlier. The numbers represent YBP averages of each expert type. The numbers in parentheses indicate the standard deviations per expert type. The mean YBP baseline for all respondents $(N=51)$, excluding the outlier, is $44(1972)$

\section{Results}

Aim 1: establishing the baseline period (Years before present) and coral cover percentage baselines

Years before present baseline question results. Survey Question:

How many years past (if any) would you use as the ecological baseline for the cover percentage for stony corals in the Florida Keys as a guide for setting restoration targets (on average throughout the keys, bank reef, an buttress zone at a depth of $10 \mathrm{~m})$ ?

The mean YBP range of all groups of respondents was 44-48; one outlier was excluded (Table 1), although the responses to this question were variable. Two of the 54 respondents did not provide an answer to this question; one claimed that an answer would not be practical. The responses to this question insignificantly changed when one outlier (6000 YBP) was excluded. The YBP range of all other responses was 12-126, while the mean YBP range for all groups of respondents was 44-48 (Table 1). 'All groups' includes respondents younger and older than 60 years, government and nongovernment workers, with less and more than 20 years of experience, as well as respondents with less and more than 1500 research dives. The overall similarity of the perspectives among the respondents with varying ages and experiences suggests that the SBS does not play a role. In addition, the lack of differences among expert types (government versus nongovernment experts) suggests that the respondent baselines are not affected by the reef expert type.

To assess the correlations between the respondent YBP baselines and age, years of experience, and number of dives (also a measure of experience), Pearson's correlation coefficients were calculated. The correlations between the YBP baseline and age, experience, or number of dives are statistically insignificant (Table 2). The majority of the respondents' baselines range from 30 to 50 YBP.

The results imply that the number of dives does not have an effect on the YBP baselines. These two factors are independent of one another. For example, the respondent with the highest number of dives $(>20,000)$ reported a YBP baseline of 47 , slightly
Table 2 Pearson's correlation coefficients $(r)$ and levels of significance $(p)$ for the correlations between the Years Before Present and age, years of experience, and number of dives.

How many years past (if any) would you use as the ecological baseline for the cover percentage for stony corals in the Florida Keys as a guide for setting restoration targets (on average throughout the keys, bank reef, and buttress zone at a depth of $10 \mathrm{~m}$ )?

\begin{tabular}{lrll}
\hline & $\boldsymbol{r}$ & $\boldsymbol{p}$ & $\boldsymbol{n}$ \\
\hline YBP vs. age & -0.074 & 0.607 & 51 \\
YBP vs. years of experience & 0.098 & 0.493 & 51 \\
YBP vs. number of dives & 0.085 & 0.559 & 50 \\
\hline No correlations were significant at $p=0.05$. & & & \\
\hline
\end{tabular}

above the average of 44 (1972). The respondent reporting the highest perceived YBP baseline (excluding the outlier) of 126 had conducted 1600 research dives in the Florida Keys, well below the average of 2564 dives reported by all respondents.

It seems that reef experts are not to affected by the SBS. In contrast, the data provide strong evidence for consensus among the different reef expert types with regard to the most appropriate time frame for the Florida Keys reef tract baseline, for example, respondents both younger $(S D=19.56)$ and older $(S D=17.32)$ than 60 reported an average YBP baseline of 44 .

Cover percentage baselines. The respondents' perspective on the cover percentage baseline for the Florida Keys bank reef system was examined by asking the following question: 'For the Florida Keys, what should the baseline cover percentage for stony corals be (on average throughout the keys, bank reef, and buttress zone at a depth of $10 \mathrm{~m})$ ?'

Several individuals provided a specific percentage and others provided a range of percentages (e.g., 30\%-35\%). Because the question asked for an average baseline, the midrange was calculated (e.g., 32.5\%) and used as the respondent's cover percentage baseline.

The mean cover percentage reported by all respondents was $33 \%$ (range of $4 \%-67 \%$; Table 3). Four of the 54 respondents did not provide a numerical response. The mean values vary little (Table 3). The coral cover of all groups of respondents ranges between 30 and $36 \%$. As mentioned above, the consistency of the response among expert types supports the view that the baselines are not affected by the reef expert type.

The distribution of the cover percentage responses was examined because the majority of the respondents' baselines were between 20 and 50\%. Four respondents (in their 30 s, 40 s, 50 s, and $80 \mathrm{~s}$, respectively) reported coral cover baselines above $60 \%$. This wide range of ages among the highest reported baselines further supports this hypothesis. On the other hand, there is a slight trend suggesting that more experienced respondents favour a slightly larger $(36 \%)$ baseline coral cover compared to less experienced interviewees (33\%). This correlation (using Pearson's correlation test) is significant at $p=0.10$. Two respondents reporting between 10-20,000 dives reported baselines ranging from $11 \%$ to $30 \%$ coral cover, less than the average baseline reported by all respondents. Therefore, long-term experience does not seem to lead to high historical coral cover estimates (Table 4).

Aim 2: what influenced the respondents' YBP and cover percentage baselines?. To assess what influenced the respondents' YBP and cover percentage baselines of the Florida Keys bank coral reef 
Table 3 Mean (standard deviation) cover percentage baselines among various respondent types.

For the Florida Keys, what should the baseline cover percentage for stony corals be (on average throughout the keys, bank reef, and buttress zone at a depth of $10 \mathrm{~m}$ )?

\begin{tabular}{lll}
\hline & M (SD) & N \\
\hline All & $33(17)$ & 50 \\
Respondents younger than 60 years old & $34(17)$ & 27 \\
Respondents age 60 and older & $33(16)$ & 23 \\
Government experts & $34(18)$ & 22 \\
Nongovernment experts (28) & $33(16)$ & 28 \\
Respondents with less than 20 years of experience & $30(18)$ & 22 \\
Respondents with more than 20 years of experience & $36(16)$ & 28 \\
Respondents with less than 1500 dives in the & $32(17)$ & 28 \\
Florida Keys & $34(14)$ & 21 \\
Respondents with more than 1500 dives in the & & \\
Florida Keys & & \\
\hline
\end{tabular}

\begin{tabular}{|c|c|c|c|}
\hline \multicolumn{4}{|c|}{$\begin{array}{l}\text { For the Florida Keys, what should the baseline cover percentage for } \\
\text { stony corals be (on average throughout the keys, bank reef, and } \\
\text { buttress zone at a depth of } 10 \mathrm{~m} \text { )? }\end{array}$} \\
\hline & $r$ & $\boldsymbol{p}$ & $n$ \\
\hline Cover percentage vs. age & 0.052 & 0.72 & 50 \\
\hline Cover percentage vs. years of experience & 0.256 & 0.072 & 50 \\
\hline Cover percentage vs. number of dives & 0.024 & 0.87 & 49 \\
\hline
\end{tabular}

tract, each expert was asked what 'informed his or her baseline'. Forty-six of 54 respondents responded (Fig. 2). The majority of the respondents indicated that they derived their baselines from the time when published data first became available. Many of the interviewees cited Dustan's early study of the Carysfort Reef (1977), indicating that this was the earliest time at which a baseline could be derived. If baselines were shifting based on the age or experience, one might expect personal observations to have the most influence on the respondents. However, the respondents indicated that they looked beyond their personal experience to establish baselines.

Aim 3: evaluating if the respondents have witnessed an Acropora sp.-dominated reef in the Florida Keys. Each respondent was asked if they had witnessed an Acropora sp.-dominated reef in the Florida Keys. Forty respondents (74\%) indicated that they had witnessed an Acropora sp. -dominated reef. Ten of the 14 respondents indicating that they had not witnessed an Acropora sp.-dominated reef were under 40 years of age. This is logical because younger scientists would not have been alive or of age to experience the reef before its significant decline. The average age of the respondents who had not experienced an Acropora sp.dominated reef was 43 years, while the average age of respondents who had witnessed an Acropora sp.-dominated reef was 61. Seventy percent of the respondents younger than 40 years old had not witnessed an Acropora sp.-dominant reef in the Florida Keys. Ninety-six percent of the respondents over the age of 60 (26 individuals) had witnessed an Acropora sp.-dominated reef. This

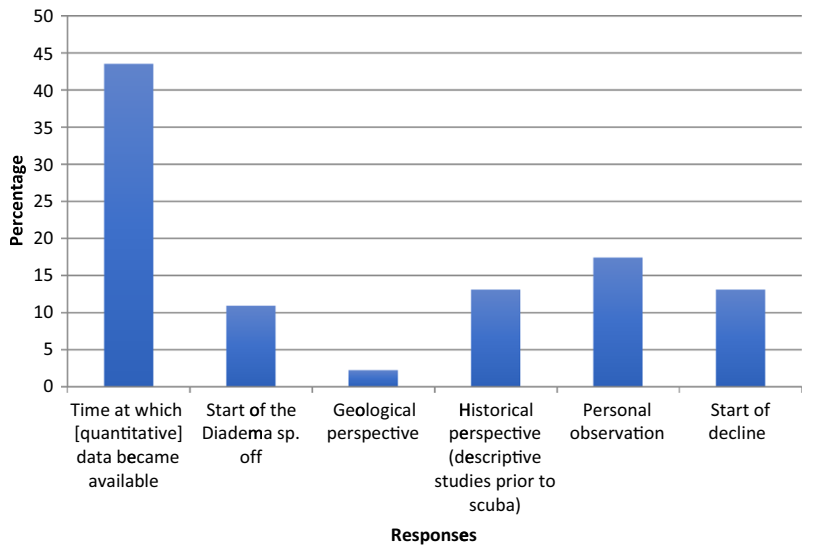

Fig. 2 Reported factors respondents used to determine their personal baselines. Responses to the question on how the respondents established their baselines for Years Before Present and cover percentage baselines $(n=46)$.

indicates that the respondents' experiences of the reef differ depending on their age, although there is no evidence that the baselines shift depending on the age.

\section{Discussion}

It is not the aim of this paper to diminish the overall validity of the SBS but to highlight the nuances of this idea, particularly among individuals with knowledge and access to peer-reviewed literature (e.g. reef experts). The results of 54 interviews with Florida Keys experts measuring different ecosystem baselines (coral cover percentage, coral YBP baselines) do not support the notion of the SBS among these experts. Based on measuring the reef YBP and coral cover percentage baselines, there is no evidence that age has a significant effect on the respondents' reported baselines. In fact, only $17 \%$ of all respondents reported using their personal observations to establish baselines. This suggests that, regardless of age, the respondents used available data including events such as the die-off of Diadema antillarum and published records of the decline of the reef to establish their baselines. These data may support the concept that experts are resistant to the SBS because they utilized available data to establish their ecosystem expectations, at least for the Florida Keys reef tract. This may indicate the lack of trust of the researchers or that they do not have enough historical or anecdotal data (beyond published ecological data) based on which they can establish meaningful baselines. Therefore, researchers promoting historical and anecdotal marine science data may need to increase the outreach to the broader reef expert community, outlining actionable management policies based on the data type. Reef experts are aware of the data but unsure how to use them to quantify baselines or other policies. Previous studies have indicated that scientists make ecosystem management decisions based on data in which they have little confidence (Cook et al., 2010, 2013; Martin et al., 2012). However, the results of this study do not support that the lack of data quality results in the SBS among reef scientists.

The prospect of using historical and social data to understand ecosystems has gained significant attention. Pauly (1995) urged scientists to 'maximize the use of the fisheries history'. Jackson (1997) stated: 'History shows that Caribbean coastal ecosystems were severely degraded long before ecologists began to study them'.

Pinnegar and Engelhard (2008) argued that ocean ecosystems have been degraded for millennia because even low-level 'artisanal' fishing can dramatically impact populations. However, only $13 \%$ of the respondents in this study mentioned historical data having an impact on their baselines. Are historical data in ecology 
rejected or simply overlooked in coral reef ecology? Is there simply a lack of resources related to historical ecology? These are logical follow-up questions. However, this study shows little evidence that historical ecological data affected the respondents' baselines because the majority of the respondents identified relatively recent quantitative data as their primary sources in establishing expectations for the Florida Keys coral reef.

This study also demonstrates a strong difference in the experience of older and younger experts regarding the Florida Keys reef tract. Seventy percent of the surveyed reef experts under the age of 40 stated that they have not witnessed an Acropora sp.dominated reef, whereas $96 \%$ of the experts over the age of 60 stated the opposite. Given this dramatic difference in personal experience, one might expect strong differences in baselines if the SBS affects respondents. However, there is no evidence for baseline differences based on the respondents' age.

This study is also significant because it demonstrates the strong consensus among the expert community regarding baselines for the Florida Keys Reef system, which has been a point of contention among reef experts for decades (Porter and Meier, 1992). Although there was one outlier, the community agreed on approximate baselines of 44 YBP (year 1972) and 33\% coral cover (on average) for this ecosystem, with available quantitative data as the primary driver of these established baselines. This work showcases the broad consensus among the expert types supporting hypothesis two. The results do not support a significant influence of the employment type because all respondents had similar occupations, a fact that may prove beneficial for coral reef conservation.

The coral cover percentage itself is variable and can be assessed by various methods. In the Florida Keys reef tract, many seascapes naturally lend themselves to a greater or lesser coral cover. Acropora sp. thickets have been studied and recorded throughout the Florida Keys prior to the significant decline (Dustan, 1977; Dustan and Halas, 1987; Vaughan, 1914; Voss, 1960) they experienced over the past four decades (Gardner et al., 2003; Shinn et al., 2003). Florida Acropora sp. habitats have been affected by cold weather (Kemp et al., 2016), disease (Harvell et al., 2004), and increased sea temperatures (Hoegh-Guldberg, 1999). Scientists have consistently debated the importance of local impacts, such as overfishing and pollution, compared with the global impacts of climate change and ocean acidification as the primary drivers of the decline (Bruno and Valdivia, 2016). Given the lack of historical data and various hypotheses presented in the scientific literature regarding coral baselines combined with the urgency of preventing coral decline, gathering expert opinions of baselines may be valuable in the development of informed coral reef management strategies. This presentation of prevailing views of coral baselines may be utilized by the scientific community to address pressing environmental concerns. Based on these established baselines, restoration ecologists and the scientific community at large may act to bring coral cover back to levels reflected in these newly established baselines.

\section{Data availability}

To protect the privacy of respondents, data generated as a result of this study will not be made public.

Received: 13 September 2019; Accepted: 25 June 2020;

Published online: 20 July 2020

\section{References}

Baisre JA (2013) Shifting baselines and the extinction of the Caribbean monk seal. Conserv Biol 27(5):927-935

Bernard RH (2002) Research methods in anthropology: qualitative and quantitative approaches, 3rd edn. Altamira Press, Walnut Creek
Bruno JF, Valdivia A (2016) Coral reef degradation is not correlated with local human population density. Sci Rep 6:29778

Campbell LM, Gray NJ, Hazen EL, Shackeroff JM (2009) Beyond baselines: rethinking priorities for ocean conservation. Ecol Soc 14(1)

Cook CN, Hockings M, Carter RW (2010) Conservation in the dark? The information used to support management decisions. Front Ecol Environ 8(4):181-186

Cook CN, Mascia MB, Schwartz MW, Possingham HP, Fuller RA (2013) Achieving conservation science that bridges the knowledge-action boundary. Conserv Biol 27(4):669-678

Cvitanovic C, Hobday AJ, van Kerkhoff L, Wilson SK, Dobbs K, Marshall NA (2015) Improving knowledge exchange among scientists and decision-makers to facilitate the adaptive governance of marine resources: a review of knowledge and research needs. Ocean Coast Manage 112:25-35

Dayton PK, Tegner MJ, Edwards PB, Riser KL (1998) Sliding baselines, ghosts, and reduced expectations in kelp forest communities. Ecol Appl 8(2):309-322

Donahue S, Acosta A, Akins L, Ault J, Bohnsack J, Boyer JDelgado G,(2008) The state of coral reef ecosystems of the Florida Keys The State of Coral Reef Ecosystems of the United States and Pacific Freely Associated States: NOAA Technical Memorandum NOS NCCOS. Vol. 73, pp. 161-187

Dustan P (1977) Vitality of reef coral populations off Key Largo, Florida: recruitment and mortality. Environ Geol 2(1):51-58

Dustan P, Halas JC (1987) Changes in the reef-coral community of Carysfort Reef, Key Largo, Florida: 1974 to 1982. Coral Reefs 6(2):91-106

Eddy TD, Cheung WW, Bruno JF (2018) Historical baselines of coral cover on tropical reefs as estimated by expert opinion. Peer J 6:e4308

Eakin CM, Morgan JA, Heron SF, Smith TB, Liu G, Alvarez-Filip L, Brandt M (2010) Caribbean corals in crisis: record thermal stress, bleaching, and mortality in 2005. PLoS ONE 5(11):e13969

Fernández-Llamazares Á, Díaz-Reviriego I, Luz AC, Cabeza M, Pyhälä A, ReyesGarcía V (2015) Rapid ecosystem change challenges the adaptive capacity of Local Environmental Knowledge. Global Environ Change 31:272-284. https://doi.org/10.1016/j.gloenvcha.2015.02.001

Gardner TA, Côté IM, Gill JA, Grant A, Watkinson AR (2003) Long-term regionwide declines in Caribbean corals. Science 301(5635):958-960

Goreau TF (1959) The ecology of Jamaican coral reefs I. Species composition and zonation. Ecology 40(1):67-90

Harvell D, Aronson R, Baron N, Connell J, Dobson A, Ellner S, Lafferty K (2004) The rising tide of ocean diseases: unsolved problems and research priorities. Front Ecol EnvirReefs since columbuson 2(7):375-382

Hoegh-Guldberg O (1999) Climate change, coral bleaching and the future of the world's coral reefs. Mar Freshw Res 50(8):839-866

Humphries P, Winemiller KO (2009) Historical impacts on river fauna, shifting baselines, and challenges for restoration. Bioscience 59(8):673-684

Jackson JB (1997) Reefs since columbus. Coral Reefs 16(1):S23-S32

Jackson JB, Kirby MX, Berger WH, Bjorndal KA, Botsford LW, Bourque BJ, Hughes TP (2001) Historical overfishing and the recent collapse of coastal ecosystems. Science 293(5530):629-637

Kahn PH Jr, Friedman B(1995) Environmental views and values of children in an inner-city black community Child Dev 66(5):1403-1417

Kemp DW, Colella MA, Bartlett LA, Ruzicka RR, Porter JW, Fitt WK (2016) Life after cold death: reef coral and coral reef responses to the 2010 cold water anomaly in the Florida Keys. Ecosphere 7(6):e01373

Knowlton N, Jackson JB (2008) Shifting baselines, local impacts, and global change on coral reefs. PLoS Biol 6(2):e54

Lapointe BE, Barile PJ, Matzie WR (2004) Anthropogenic nutrient enrichment of seagrass and coral reef communities in the Lower Florida Keys: discrimination of local versus regional nitrogen sources. J Exp Mar Biol Ecol 308(1):23-58

Lessios HA, Robertson DR, Cubit JD (1984) Spread of Diadema mass mortality through the Caribbean. Science 226(4672):335-337

Lirman D, Fong P (1997) Patterns of damage to the branching coral Acropora palmata following Hurricane Andrew: damage and survivorship of hurricanegenerated asexual recruits. J Coast Res 13(1):67-72

Martin TG, Burgman MA, Fidler F, Kuhnert PM, Low-Choy S, McBride M, Mengersen K (2012) Eliciting expert knowledge in conservation science. Conserv Biol 26(1):29-38

McClenachan L (2009) Documenting loss of large trophy fish from the Florida Keys with historical photographs. Conserv Biol 23(3):636-643

McClenachan L, O'Connor G, Neal BP, Pandolfi JM, Jackson JB (2017) Ghost reefs nautical charts document large spatial scale of coral reef loss over 240 years. Sci Adv 3(9):e1603155

Mooallem J (2017) Our climate future is actually our climate present. The New York Times Sunday Magazine. https://www.nytimes.com/2017/04/19/ magazine/ourclimate-future-is-actually-our-climate-present.html

Office of National Marine Sanctuaries (2011) Florida Keys National Marine Sanctuary Condition Report 2011. U.S. Department of Commerce, National Oceanic and Atmospheric Administration, Office of National Marine Sanctuaries, Silver Spring

Olsen R (2002) Slow-motion disaster below the waves. Los Angeles Times. http:// articles.latimes.com/2002/nov/17/opinion/op-olson 17 
Papworth SK, Rist J, Coad L, Milner Gulland EJ (2009) Evidence for shifting baseline syndrome in conservation. Conserv Lett 2(2):93-100

Pauly D (1995) Anecdotes and the shifting baseline syndrome of fisheries. Trends Ecol Evol 10(10):430

Pinnegar JK, Engelhard GH (2008) The 'shifting baseline' phenomenon: a global perspective. Rev Fish Biol Fisher 18(1):1-16

Porter JW, Meier OW (1992) Quantification of loss and change in Floridian reef coral populations. Am Zool 32(6):625-640

Precht WF, Miller SL (2007) Ecological shifts along the Florida reef tract: the past as a key to the future. In: Aronson RB (ed) Geological approaches to coral reef ecology. Springer, New York, pp. 237-312

Ruzicka R, Coella M, Semon K, Brinkhuis V, Morrison J, Kidney J, Porter J, Meyers M, Christman M, Colee J (2010) CREMP 2009 Final Report. Fish and Wildlife Research Institute/Florida Fish and Wildlife Conservation Commission, Saint Petersburg

Saenz-Arroyo A, Roberts C, Torre J, Carino-Olvera M, Enriquez-Andrade R (2005) Rapidly shifting environmental baselines among fishers of the Gulf of California. P Roy Soc B-Biol Sci 272(1575):1957-1962

Sheppard S (1995) The shifting baseline syndrome. Mar Pollut Bull 30(12):766767

Shinn EA, Reich CD, Hickey TD, Lidz BH (2003) Staghorn tempestites in the Florida Keys. Coral Reefs 22(2):91-97

Soga M, Gaston KJ (2018) Shifting baseline syndrome: causes, consequences, and implications. Front Ecol Environ 16(4):222-230

United States Department of Commerce (2016) National Oceanic and Atmospheric Administration. National Marine Fisheries Service. Status of stocks 2016: Annual report to congress on the status of U.S. fisheries

Vaughan TW (1914) Investigations of the geology and geological processes of the reef tracts and adjacent areas of the Bahamas and Florida. Carnegie Institute, Washington. pp. 121-183

Voss GL (1960) First underseas park. Sea Front 6:87-94

\section{Acknowledgements}

This research was conducted as part of a doctoral dissertation at George Mason University. We thank dissertation advisors Dr. Esther Peters and Dr. Clayton B. Cook. We also thank Wilmington University for tuition support during completion of the degree Lastly, we thank NASA Delaware Space Grant College and Fellowship Program (NASA Grant NNX15AII9H) for their support.

\section{Competing interests}

The authors declare no competing interests.

\section{Additional information}

Supplementary information is available for this paper at https://doi.org/10.1057/s41599 020-0526-0.

Correspondence and requests for materials should be addressed to M.M.Jr.

Reprints and permission information is available at http://www.nature.com/reprints

Publisher's note Springer Nature remains neutral with regard to jurisdictional claims in published maps and institutional affiliations

(c) (i) Open Access This article is licensed under a Creative Commons Attribution 4.0 International License, which permits use, sharing, adaptation, distribution and reproduction in any medium or format, as long as you give appropriate credit to the original author(s) and the source, provide a link to the Creative Commons license, and indicate if changes were made. The images or other third party material in this article are included in the article's Creative Commons license, unless indicated otherwise in a credit line to the material. If material is not included in the article's Creative Commons license and your intended use is not permitted by statutory regulation or exceeds the permitted use, you will need to obtain permission directly from the copyright holder. To view a copy of this license, visit http://creativecommons.org/ licenses/by/4.0/

(C) The Author(s) 2020 